\title{
Identification and Analysis of Converging Technology Based on Patent Co-Classification Relationship
}

\author{
Lucheng Lv, Tao Han, Yajuan Zhao, Xuezhao Wang, Ping Zhao \\ National Science Library, Chinese Academy of Sciences, Beijing, 100190, P. R. China \\ lvlc@mail.las.ac.cn; hant@mail.las.ac.cn; zhaoyj@mail.las.ac.cn; wangxz@mail.las.ac.cn; zhaop@mail.las.ac.cn
}

\begin{abstract}
Patent documents are an ample source for technical knowledge, and increased dramatically in recent years. This paper aims at identifying and analyzing converging technology based on patent analysis. The identification method of Converging technology is through cluster analysis based on USPC cooccurrence matrix calculated by the cross USPC class patents of five parties during the 2005-2015 years. Finally, 161 converging technologies are identified. Converging technology is mainly distributed in the new generation of information technology, new material industry. High end equipment manufacturing industry is the most active industry in technological convergence. ${ }^{1}$
\end{abstract}

\section{KEYWORDS}

Patent data mining, Converging Technology, Co-Classification Analysis, Technical activity

ACM Reference Format:

Lucheng Lv, Tao Han, Yajuan Zhao, Xuezhao Wang, and Ping Zhao. 2018. Identification and Analysis of Converging Technology Based on Patent Co-Classification Relationship. In JCDL '18: The 18th ACM/IEEE Joint Conference on Digital Libraries, June 3-7, 2018, Fort Worth, TX, USA. ACM, New York, NY, USA, 2 pages. https://doi.org/10.1145/3197026.3203903

\section{INTRODUCTION}

Converging technology is the product of technological convergence. The identification and analysis of converging technology has positive effects on recognizing the trend of technological convergence and guiding the research direction and industrial distribution. Accordingly, there are many research papers on technological convergence. Since the concept of technological convergence was first proposed in Rosenberg's research on the evolution of the US Machine Tool Industry[1], many authors have tried to develop similar conceptions of convergence and put forward various analysis method.

Patent documents are an ample source for technical knowledge, and increase dramatically in recent years. In particular, patents have been employed for the technology driven convergence. A representative example is the paper of Geum et al.[2] which takes a

Permission to make digital or hard copies of part or all of this work for personal or classroom use is granted without fee provided that copies are not made or distributed for profit or commercial advantage and that copies bear this notice and the full citation on the first page. Copyrights for third-party components of this work must be honored. For all other uses, contact the Owner/Author.

JCDL '18, fune 3-7, 2018, Fort Worth, TX, USA

(c) 2018 Copyright is held by the owner/author(s)

ACM ISBN 978-1-4503-5178-2/18/06.

https://doi.org/10.1145/3197026.3203903 quantitative approach by citation analysis and co-classification analysis to analyze the technological convergence of information technology (IT) and biotechnology(BT).

With the rapid development of the Internet, $\mathrm{AI}$ and robotics in recent years, the trend of technological convergence is more and more obvious. Under such an environment, what is the new converging technology? Which industries are they distributed in?

This paper aims at identifying and analyzing converging technology based on patent analysis. Research method is coclassification analysis because citation analysis has the problem of time lag. A patent classification was arranged by the examiners of a patent office according to the technical features of inventions. Since the same document may be classified in several classes, the coclassification information can be used to identify the relationships between technologies. The relevant method was later applied in a science and technology context [3]. Based on this, we assume that technologies with a high degree of co-classification are converging technologies.

\section{DATASET AND METHODS}

Figure 1 shows the specific process, like the following:

s1. Download 79986 quintuple patent families during the 20052015 years from Incopat database. Quintuple patent family means patent in family granted in China and the US, and applied in Europe, Japan and South Korea.

s2. Select the cross USPC class patents, and the number is 36880 .

s3. Calculate the USPC co-occurrence matrix based on the cooccurrence relationship of USPC, and the dimension is 13512 .

s4. Cluster based on the USPC co-occurrence matrix by the hierarchical clustering, and obtained 161 clusters, that is, 161 converging technologies.

s5. Interpret the converging technology and establish the mapping relationship between converging technology and strategic emerging industries and sub-industries through domain experts. The list of strategic emerging industries was released by the National Development and Reform Commission, including seven industries and related sub-industries.

s6. Draw converging technical structure map based on industrial relation of converging technology.

s7. Analyze the technical activity(TA) of converging technologies. Equation 1 is the calculation of TA. $Y_{n}$ is the latest patent application year in converging technology. $Y_{m}$ is the most patent application year in converging technology.

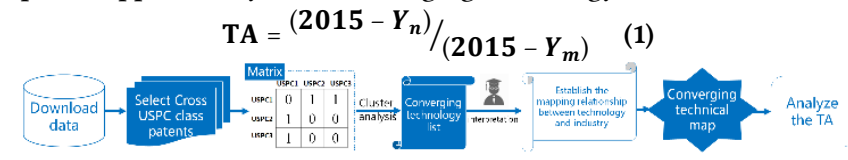

Figure 1: Process of the study 


\section{RESULTS}

Figure 2 shows the distribution of industries of converging technologies. Here are seven strategic emerging industries and one "other traditional industries" that refers to converging technologies that don't belong to the strategic emerging industries.

Figure 3 shows converging technical structure map of 161 converging technologies. Each circle represents a converging technology. The size of a circle represents the number of the quintuple patent families in the converging technologies. The color of the circle represents the industrial classification of the converging technology. The line between circles indicates that two converging technologies belong to a certain emerging sub-industry. The thickness of the lines is proportional to the number of same emerging sub-industries between two converging technology. The lines between circle of different colors represent that converging technology is cross-industry.

Figure 4 shows distribution of the average TA of industries. The smaller TA value, the more active.

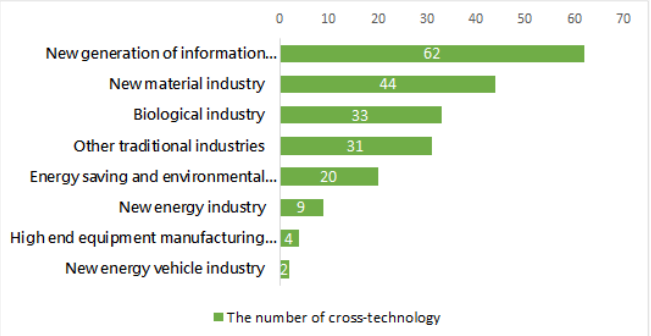

Figure 2: Distribution of industries of converging technologies

Table 1 lists 4 cross-industry and TA $\geqslant 4$ cross-industry converging technologies. The column named as "Description of Technology" shows technology interpretation. The column named as "Associated Industries" shows several industries that converging technology can be used.

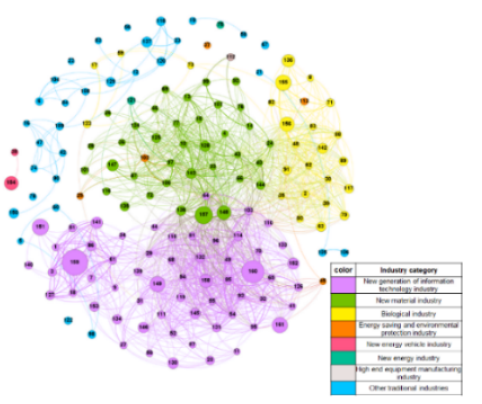

Figure 3: Converging technical structure map

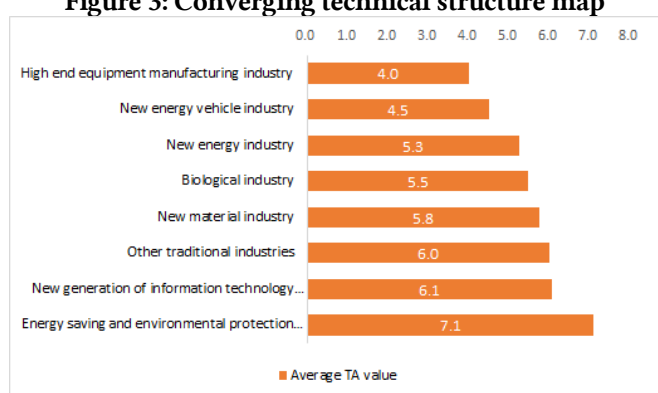

Figure 4: Distribution of the average TA value of industries

\section{CONCLUSIONS}

In this paper, 161 converging technologies are identified. Most of the converging technologies are converging in the same industry. The new generation of information technology, new material industry and biological industry are the top 3 industries of converging technologies. High end equipment manufacturing industry is the most active industry

\begin{tabular}{|c|c|c|}
\hline $\begin{array}{l}\text { Converging } \\
\text { Tech No }\end{array}$ & Description of Technology & Associated Industries \\
\hline No.65 & $\begin{array}{l}\text { Related manufacturing methods and process engineering of liquid } \\
\text { crystal, light emitting diode and other display devices, semiconductor } \\
\text { light emitting devices and so on. }\end{array}$ & $\begin{array}{l}\text { Energy saving and environmental } \\
\text { protection industry, New generation of } \\
\text { information technology industry }\end{array}$ \\
\hline No.97 & $\begin{array}{l}\text { The preparation of the whole carbon family and its composite } \\
\text { materials and its application in the fields of photoelectric and heat. }\end{array}$ & $\begin{array}{l}\text { New material industry, New energy } \\
\text { industry, Energy saving and environmental } \\
\text { protection industry }\end{array}$ \\
\hline No.115 & $\begin{array}{l}\text { Manufacturing methods and technology of solar cell; Related } \\
\text { manufacturing methods and technology of other photoelectric } \\
\text { conversion elements such as solid state image sensor. }\end{array}$ & $\begin{array}{l}\text { New generation of information technology } \\
\text { industry, New energy industry }\end{array}$ \\
\hline No.154 & $\begin{array}{l}\text { Robotics, such as control systems, visual and voice systems and so } \\
\text { on; Power and control technology of electric vehicle/hybrid vehicle; }\end{array}$ & $\begin{array}{l}\text { High end equipment manufacturing } \\
\text { industry, New energy vehicle industry }\end{array}$ \\
\hline
\end{tabular}

Table 1: Cross-industry and $T A \geqslant 4$ converging technologies (For lack of space, only show part of the result)

\section{REFERENCES}

[1] Rosenberg N. Technological Change in the Machine Tool Industry, 18401910[J]. Journal of Economic History, 1963, 23(4):414-443.
[2] Geum Y, Kim C, Lee S, et al. Technological Convergence of IT and BT: Evidence from Patent Analysis[J]. ETRI Journal, 2012, 34(3):439-449

[3] Tijssen R J W. A quantitative assessment of interdisciplinary structures in science and technology: Co-classification analysis of energy research [J]. Research Policy, 1992, 21(1):27-44 